\title{
The Role of Magnetite Nanoparticles (ICNB) in Discovery New Factor Which Influence on Permeability of Erythrocytes and Eryptosis
}

\author{
Andrey Belousov \\ Laboratory of Applied Nanotechnology of Belousova Engineering Invest IF GmbH, Kharkov Medical Academy of \\ Postgraduate Education, Kharkov, Ukraine \\ Email: an.belousov2012@yandex.ua, andrey.belousov@eng-invest.at
}

Received 25 August 2014; revised 4 October 2014; accepted 6 November 2014

Copyright (C) 2014 by author and OALib.

This work is licensed under the Creative Commons Attribution International License (CC BY). http://creativecommons.org/licenses/by/4.0/

(c) () Open Access

\section{Abstract}

This paper presents original research studying the effects of biocompatible nanoparticles standardized (ICNB) on the permeability of erythrocytes and eryptosis. The presented evidence demonstrates that changing orientation and mobility protons of the hydrogen atoms in the pericellular fluid significantly modify the permeability and physiological activity of erythrocytes. The leading role of the state of cell membrane and transport activity enzymes (ATPase) in ensuring its permeability and functional activity is exaggerated. Magnetite nanoparticles (ICNB) act on the fluid of pericellular structure by changing the orientation and mobility of hydrogen protons that ultimately determines the permeability, and physiological activity of cells. These studies support the G. Ling's theory of an "association-induction" and "multi-layered organization polarized water".

\section{Keywords}

Nanoparticles of ICNB, Permeability, Physiological Activity, Erythrocytes, Mobility of Protons of the Hydrogen Atoms, Eryptosis

Subject Areas: Clinical Trials, Nanometer Materials

\section{Introduction}

Restoration of the metabolic process, prolonging time of normal functioning of the cells inside and outside the body an organism is the main task of medical and biological direction in XXI century. Will it possible in the near future to purposefully control metabolism of cells to treat incurable diseases? What kind of tools and methods should be used for it? All these questions can be answered by a modern branch of science-nanotechnology [1]. It is a mistake to look at nanopreparations only from the view of pharmacology. First of all nanopar- 
ticles are nanotools whereby we can alter the structure of molecules outside and inside the area of cells, change them, study new reactions and metabolic mechanisms of cells. This is the key for the discovery and understanding of the functioning of cells, their life and death. Previously the complex investigations that were performed in the study of the influence on metabolism of cells by preparations of nanotechnology (Micromage-B, MCS-B, and ICNB) showed that magnetite nanoparticles had nonspecific modulated effect on metabolic processes. It is well established that the magnetite nanoparticles effectively modulate the metabolic processes in leukocytes, regulate activity of the enzyme link of the antioxidant system in erythrocytes in healthy and sick patients [2] [3]. Research of ultrastructure the reticuloendothelial system (liver, lungs and kidneys) it was proved that after injection magnetite nanoparticles into a vein caused nonspecific activation of the metabolic processes, increase adaptive mechanisms and potential of organelle cells, acceleration of reparative processes on a level of membranes and macromolecules [4] [5].

Existing sorption and indirect (magnetic) effects not only allow selectively absorbing the protein of surface membrane cells by magnetite nanoparticles (according to the principle of magnetophoreses), but also prevent the oxidative modification of proteins by way of stabilizing the active groups, normalizing a state of receptors that are located on the surface membrane of cells, increasing activity of enzymes' membrane-bound [6] [7]. Recent scientific work related to use of magnetite nanoparticles (ICNB) in contrast means in an MRI investigation of cancer reliably had shown that nanoparticles cause reversible changes associated with a temporary increase in the mobility of hydrogen protons in the pericellular fluid that inevitably modifies the metabolism in malignant cells [8]. The results of these investigations have not only widened the understanding of the mechanisms of action of nanoparticles on condition outside and intracellular spaces but also have revealed new aspects of the cellular(cells) metabolism, determined the membrane role of cellular enzymes in the regulation processes of metabolism [9].

Based on the foregoing the study of the influence on mechanism permeability of cells by magnetite nanoparticles was the continuation of current scientific work. It was necessary to find answers to the following questions: why does the sorption of surface proteins membrane of erythrocytes by magnetite nanoparticles not only increase their resistance to destroy but also prolong functional activity of blood cells, in several times prolong the storage time?

The main purpose: to change the permeability of the cells by means of standardized biocompatible magnetite nanoparticles (ICNB).

In order to perform this goal were set next tasks:

1) It is necessary to create a simple of model that will demonstrate the permeability of cells.

2) To present evidence of dates about changing the permeability of the cells.

3) To investigate different variations of environments which affect extracellular space.

4) To line up the logistic chain continuity obtained by scientific dates with early data.

\section{Materials and Methods}

Standardized intracorporeal nanobiocorrector of ICNB was taken as nanoparticles [10]. The main physics and chemical properties of ICNB include:

-Concentration of the colloidal solution of magnetite nanoparticles in physiology solution of $\mathrm{NaCl}$ is $0.0225 \%$;

-Theoretical osmolality of colloid solution is $500 \mathrm{mosmol} / \mathrm{l}$;

-Size of magnetite nanoparticles is 6 - $12 \mathrm{~nm}$;

-Total area of surface magnetite of nanoparticles $\mathrm{S}_{\mathrm{s}}=800-1200 \mathrm{~m}^{2} / \mathrm{g}$;

-Magnetization of saturation $\mathrm{I}_{\mathrm{s}}=2.15 \mathrm{\kappa A} / \mathrm{m}$;

$-\zeta$-potential $=-19 \mathrm{mV}$.

Before starting the main experience on the MRI we used visual assessment by comparison the brightness of the imagines in other experimental fluids. These were: ICNB, physiology solution of $\mathrm{NaCl}$ and physiology solution of $\mathrm{NaCl}$ that has previously been treated with ICNB.

The tests were performed on the Siemens MR-tomagraphy Magnetron Concerto with power magnetic-field $0.2 \mathrm{~T}$.

The axial tomograms were received:

1) T1, the self-weighted sequences of Echo Spin of TR $50 \mathrm{~ms}$, TE $17 \mathrm{~ms}$ the field of review the $250 \mathrm{~mm}$, the 
thickness cut $2 \mathrm{~mm}$.

2) T2, the self-weighted sequences Echo Gradient of TR $500 \mathrm{~ms}$, TE $17 \mathrm{~ms}$ the field of review the $180 \mathrm{~mm}$, the thickness cut $4 \mathrm{~mm}$.

Erythrocytes of venous blood of the healthy person were the study materials of the cells permeability. $2 \mathrm{ml}$ of blood were distributed in four tubes with citrate. Intercellular space was simulated by adding physiological solution $\mathrm{NaCl}$ in tubers. The distribution of tubers was as follows:

Tube I: $2 \mathrm{ml}$ of blood $+1 \mathrm{ml} 0.9 \%$ solution of $\mathrm{NaCl}$.

Tube II: $2 \mathrm{ml}$ of blood $+1 \mathrm{ml} 0.9 \%$ solution of $\mathrm{NaCl}+1 \mathrm{ml}$ distillate water.

Tube III: $2 \mathrm{ml}$ of blood $+1 \mathrm{ml} 0.9 \%$ solution of $\mathrm{NaCl}$ that had previously been treated ICNB $+1 \mathrm{ml}$ distillate water.

Tube IV: $2 \mathrm{ml}$ of blood $+1 \mathrm{ml} 0.9 \%$ solution of $\mathrm{NaCl}+1.0$ ICNB $+2 \mathrm{ml}$ distillate water.

The change of erythrocyte membrane permeability was determined visually and microscopically, registering sings of hemolysis.

Tests were carried out in two stages: in 1 hour and on day 10 .

\section{Results and Discussion}

Results of visual assessment of the images brightness used in experiment liquids at the MRI are represented in Figure 1.

Figure 1 illustrates the difference of image brightness in liquids compared at the MRI. The order of the brightness increase is the following: ICNB, physiologic solution $\mathrm{NaCl}$, physiologic solution $\mathrm{NaCl}$ that was treated by nanoparticles of ICNB. The difference in brightness of images is explained in the following way:

Variant 1. Magnetite nanoparticles of ICNB reduce the mobility of hydrogen protons in the liquid medium $(0.9 \%$ solution of $\mathrm{NaCl})$. Therefore, the image brightness was very low in the MRI.

Variant 2. Rising mobility of hydrogen protons in the intact $0.9 \%$ solution of $\mathrm{NaCl}$ increased brightness in comparison with Variant 1.

Variant 3. Mobility of hydrogen protons in $0.9 \%$ solution of $\mathrm{NaCl}$ that has previously been processed ICNB nanoparticles is maximized. Therefore, the image brightness is much higher than before (in the previous variants).

Thus, previously conducted research clearly shows that the nanoparticles of ICNB change the mobility and the orientation of the hydrogen atoms in liquids that are registered in the visual evaluation of MRI.

The next set of studies was essential and aimed at studying of cell permeability changes by modifying the mobility and spatial orientation of hydrogen protons in the pericellular fluid using magnetite nanopatricles of ICNB.

Results of the visual assessment of the permeability of erythrocytes in various aspects of exposure are presented in Figure 2.

Figure 2 shows that the colloidal suspension system of blood stratifies under the influence of gravity for an hour after starting the test. Appearance of the plasma reddish in colour indicates on the phenomena of the hemolysis.

Thus, an hour after introducing physiologic solution $\mathrm{NaCl}$ into venous of blood, blood plasma was of light
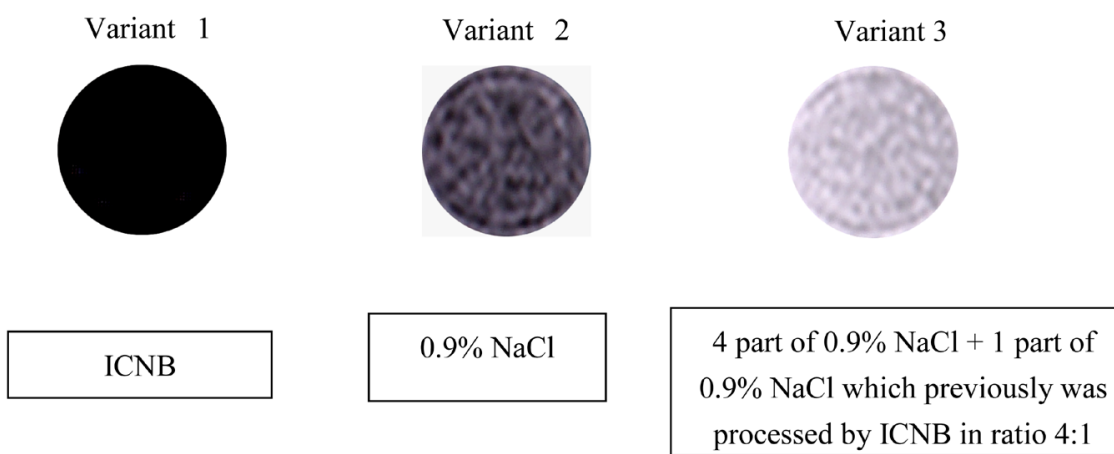

Figure 1. Images of fluids that were studied in the research at the MRI. 


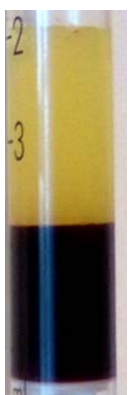

1

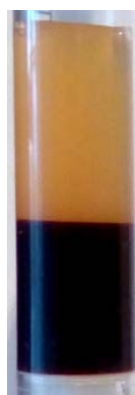

2

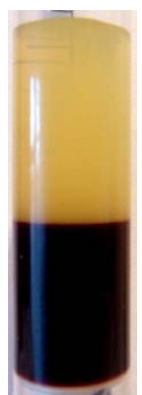

3

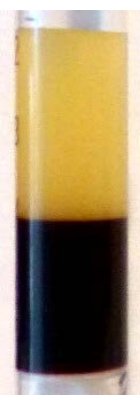

4

Notes: 1-blood + physiologic solution $\mathrm{NaCl}$ (control); $2-$ blood + physiologic solution $\mathrm{NaCl}+$ distilled water; 3blood + physiologic solution $\mathrm{NaCl}$ which treated by nanoparticles of ICNB + distilled water; 4-blood + physiologic solution $\mathrm{NaCl}+$ nanoparticles of ICNB + distilled water.

Figure 2. Visual assessment of erythrocytes membrane permeability in different stages of impact on the extracellular fluid status in 1 hour after blood collection.

yellow color in first test tube (control). This fact indicates the absence of hemolysis. Typical size of erythrocytes by microscopic examination testifies that the injected solution was isotonic.

In the second test tube plasma obtained a reddish hue when distilled water was added into the blood on the background of physiologic solution $\mathrm{NaCl}$. Sizes of erythrocytes were dramatically increased by microscopic examination. Here and there damaged cells were seen. Increasing of cell permeability in results of reducing the osmolarity of the pericellular fluid caused cell destruction. If pericellular water is in excess amount it penetrates into erythrocyte and destroys an erythrocyte. Free hemoglobin that is coming out of the erythrocytes colors the plasma a reddish color.

In the third test tube the addition of distilled water has not caused the changes in color of the plasma where physiologic solution $\mathrm{NaCl}$ has been previously treated by nanoparticles of ICNB. Sizes of erythrocytes stayed typical by microscopic examination.

In the fourth test tube the same as in the third one inserted distilled water has not caused the pathological changes in color of plasma and sizes of erythrocyte where blood with physiologic solution $\mathrm{NaCl}$ and ICNB.

The next phase of the investigation (stage II) was performed on the 10th day of observation after the blood was collected. Results of the visual assessment of the permeability of erythrocytes in various stages of exposure on stage II (10th day) are presented in Figure 3.

Figure 3 shows that on 10th day the part of plasma proteins is stratifies under the gravity influence gravity is stratified and the blood serum appears more translucent.

In the first test tube (control) bottom layer of serum was a bright red color. This fact indicates the presence of free hemoglobin in serum. The microscopic sizes of the erythrocytes were increased dramatically. Huge number of disrupted cells was seen.

The cause of the destruction of cells was dysfunction of their permeability in the result of eryptosis activation.

In the second test tube bottom layer of serum was also a bright red color where distilled water has been added in the blood with the physiological solution. The appearance of a bright red color in the bottom layer of serum (as control) indicates the presence of free hemoglobin. The microscopic sizes of the erythrocytes were increased dramatically. Huge number of disrupted cells was determined. The cause of the destruction of the cells was not only dysfunction of their permeability in the result of eryptosis activation but also as a result of low pericellular fluid osmolarity.

In the third test tube with blood, there were not observed any color changes of serum on the 10th day where physiologic solution $\mathrm{NaCl}$ was pretreated by magnetite nanoparticles of ICNB and distilled water was added. Sizes of erythrocytes stayed typical by microscopic examination.

In the fourth test tube the same as in the third test one there were not seen any pathologic color change of serum and size of erythrocytes where the distilled water was added in the blood with physiologic solution $\mathrm{NaCl}$ and ICNB. 


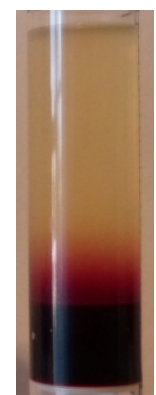

1

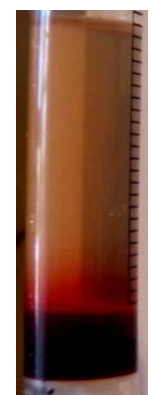

2

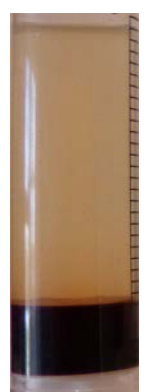

3

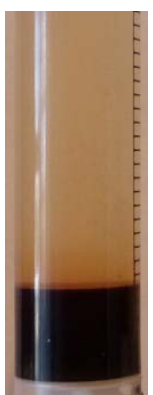

4

Notes: 1-blood + physiologic solution $\mathrm{NaCl}$ (control); 2blood + physiologic solution $\mathrm{NaCl}+$ distilled water; 3-blood + physiologic solution $\mathrm{NaCl}$ which treated by nanoparticles of ICNB + distilled water; 4-blood + physiologic solution $\mathrm{NaCl}$ + nanoparticles of ICNB + distilled water.

Figure 3. Visual assessments of erythrocytes permeability in different stages impact on the status extracellular fluid on 10th day.

The obtained results in the test tubes 3 and 4 demonstrate not only show efficiency of blood cells stability for permeability of distilled water and inhibiting effect of eryptosis.

Thus, in this case the change in orientation and mobility of hydrogen protons in the pericellular fluid has crucial for permeability and physiological activity of the blood cells. Consequently existing opinion is unrealistic about central role of the cell membrane state and transport activity of enzymes (ATPases) in ensuring its permeability and functional activity.

The conducted experiment with the use of magnetite nanoparticles (ICNB) demonstrates that the permeability of the cell firstly depends on a condition structure of the pericellular fluid. We change the permeability of the cell and its physiological activity after restructuring the pericellular fluid. These studies support the G. Ling's theory of an "association-induction" and "multi-layered organization of polarized water" [11].

\section{Conclusions}

1) Magnetite nanoparticles of ICNB reduce mobility of hydrogen protons in a liquid medium ( $0.9 \%$ solution of $\mathrm{NaCl}$ ). As a result was registered on the MRI decrease brightness of image.

2) Orientation and mobility of hydrogen protons are changing in physiologic solution of $\mathrm{NaCl}$ that has previously been processed by nanoparticles of ICNB. This fact was recorded by increasing on the MRI brightness of image.

3) It is established that the change in orientation and mobility of the hydrogen protons in the pericellular fluid modifies the permeability of and physiological activity of the blood cells.

4) Magnetite nanoparticles (ICNB) and physiologic solution of $\mathrm{NaCl}$ that preliminary was processed by INCB had altered the permeability of the blood cells and inhibited the eryptosis.

5) Leading role of the cell membrane state and transport activity of enzymes (ATPases) is exaggerated in ensuring its permeability and functional activity.

6) New factor affecting permeability of erythrocytes and eryptosis was discovered.

\section{References}

[1] http://nanolab.com.ua/abstracts.html

[2] Belousov, A.N. and Belousova, E.Yu. (2002) The First Steps in Discovery New Mechanisms of Cellular Regulation in Means by Nanotechnology Preparations. X International Conference New Information Technologies in Medicine and Ecology, Yalta, 420-425.

[3] Belousov, A.N. (2000) Effect of Magnet Controlled Sorbent on Parameters of Acid-Base Balance of the Blood and the Processes of Glycolysis in Erythrocytes. Pain, Anesthesia and Intensive Care, 1, 263-265.

[4] Belousov, A.N. and Nevzorov, V.P. (1997) Ultrastructure of Cells in the Kidneys and Lungs of Rabbits after Administration of Magnetite. International Collection of Scientific Papers IV Scientific and Practical Conference on the Crea- 
tion and Testing of New Drugs, 4, 77-87.

[5] Belousov, A.N. and Nevzorov, V.P. (1997) Ultrastructure of Liver Cells after Administration of Magnetite. International Collection of Scientific Papers IV Scientific and Practical Conference on the Creation and Testing of New Drugs, 4, 71-77.

[6] Belousov, A.N. (2009) Spectrum of Application Magnetite Nanopaticles in Medicine. Nanotech, 2, $154-157$.

[7] Belousov, A.N. (2012) Effect on Hemolysis and Transport ATPase Activity of Erythrocytes by Means Nanopareticles of Magnetit Controlled Sorbent (MCS-B). Pain, Anesthesia and Intensive Care, 1, 26-28.

[8] Belousov, A.N. (2013) Application Magnetite of Nanoparticles (ICNB Preparation) as Magnetically-Resonant Contrasting Means during Visualization of Tumours. Clean Technology and Sustainable Industries Organization, 10, 379381.

[9] Belousov, A.N. (2012) Investigation of the Influence Nanoparticles of Magnetite Controlled Sorbent (MCS-B) on the Functional Activity of Erythrocytes. Prospects Medicine and Biology, 1, 94-97.

[10] www.nanolab.com.ua

[11] Ling, G.N. (2008) Life at the Cell and Below-Cell Level: The Hidden History of a Fundamental Revolution in Biology. Science, Sankt-Peterburg, 376 p. 